05

\title{
Термовольтаический эффект \\ в полуторном сульфиде церия
}

\author{
(C) В.В. Каминский ${ }^{1}$, С.М. Соловьёв ${ }^{1}$, Н.В. Шаренкова ${ }^{1}$, \\ Shinji Hirai ${ }^{2}$, Yohei Kubota ${ }^{2}$ \\ ${ }^{1}$ Физико-технический институт им. А.Ф. Иоффе РАН, Санкт-Петербург, \\ Россия \\ ${ }^{2}$ Muroran Institute of Technology, Muroran, Hokkaido, Japan \\ E-mail: vladimir.kaminski@mail.ioffe.ru
}

Поступило в Редакцию 2 февраля 2018 г.

Обнаружен термовольтаический эффект в полуторном сульфиде церия $\left(\mathrm{Ce}_{2} \mathrm{~S}_{3}\right)$. Измерения проведены в температурном интервале $300-455 \mathrm{~K}$. Максимальная величина генерируемого напряжения составила $\sim 60 \mathrm{mV}$, однако на долю термовольтаического эффекта пришлось $37 \mathrm{mV}$.

DOI: 10.21883/PJTF.2018.23.47014.17235

Термовольтаический эффект впервые был найден в редкоземельном полупроводниковом соединении $\mathrm{SmS}$ [1]. Впоследствии эффект был обнаружен также в $\mathrm{ZnO}$ [2], соединениях $\mathrm{Ge}$ и $\mathrm{Si}$ [3] и некоторых других полупроводниках. Термовольтаический эффект перспективен для преобразования тепловой энергии в электрическую, и поэтому поиски новых материалов с большой величиной генерируемого напряжения актуальны.

Известно, что полуторные сульфиды церия с небольшим отклонением от стехиометрии $\mathrm{Ce}_{2+x} \mathrm{~S}_{3}$, где $0<x<0.225$, являются невырожденными полупроводниками, сопротивление которых при $T=300 \mathrm{~K}$ резко уменьшается (на несколько порядков величины) при увеличении $x$. При этом концентрация электронов проводимости изменяется в интервале $(0.05-140) \cdot 10^{19} \mathrm{~cm}^{-3}[4]$. Это свойство указанных соединений позволяет надеяться на возможность создания на их основе гетероструктур с большим градиентом электрических параметров, и, как указано в [5], такие структуры могут быть применены для исследования термовольтаического эффекта [6]. Настоящая работа посвящена выяснению 


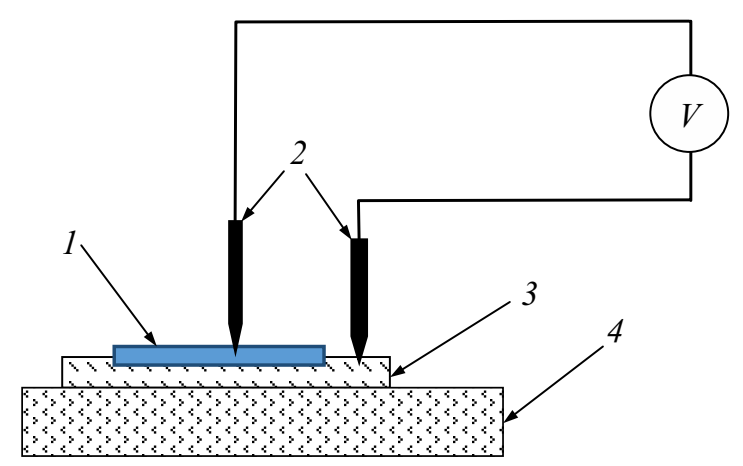

Pис. 1. Схема эксперимента. 1 - поликристаллический образец $\mathrm{Ce}_{2} \mathrm{~S}_{3}, 2-$ прижимные контакты, 3 - металлическая подложка, 4 - нагреватель.

возможности обнаружения термовольтаического эффекта в полуторных сульфидах церия.

Порошок $\mathrm{Ce}_{2} \mathrm{~S}_{3}$ был синтезирован способом, описанным в [5]. По результатам рентгеноструктурного фазового анализа синтезированный порошок имел следующий состав: $\gamma$-фаза $\mathrm{Ce}_{2} \mathrm{~S}_{3} \sim 40 \%, \beta$-фаза $\mathrm{Ce}_{2} \mathrm{~S}_{3} \sim 30 \%, \mathrm{Ce}_{10} \mathrm{~S}_{14} \mathrm{O} \sim 30 \%$. Последнее соединение имеет такую же тетрагональную структуру, как и $\beta$-фаза. Таким образом, мы имеем состав, соответствующий химической формуле $\mathrm{Ce}_{2} \mathrm{~S}_{3}$, в котором примерно каждый пятидесятый ион заменен ионом кислорода. Характерные размеры областей когерентного рассеяния рентгеновского излучения составляли около $800 \AA$ для $\gamma$-модификации $\mathrm{Ce}_{2} \mathrm{~S}_{3}$ и $400 \AA$ для $\beta$-модификации $\mathrm{Ce}_{2} \mathrm{~S}_{3}$ и $\mathrm{Ce}_{10} \mathrm{~S}_{14} \mathrm{O}$. Образец $\mathrm{Ce}_{2} \mathrm{~S}_{3}$ был спрессован из порошка под давлением $15 \mathrm{MPa}$. Полученный поликристалл имел следующие размеры: толщина $0.25 \mathrm{~mm}$ и диаметр $6 \mathrm{~mm}$. Его удельное электросопротивление при $T=300 \mathrm{~K}$ составляло $1.5 \cdot 10^{6} \Omega \cdot \mathrm{cm}$.

На рис. 1 представлена схема эксперимента по измерению термовольтаического эффекта. Образец 1 помещен на металлическую пластину 3. Пластина расположена на нагревателе 4 и служит нижним контактом к образцу. Выходной сигнал снимается токовыводами 2, подключенными к вольтметру $V$. Вольтметр и нагреватель подключены через порты USB и RS232 к управляющему компьютеру. Управление экспериментом осуществлялось при помощи программы LabVIEW.

Письма в ЖТФ, 2018, том 44, вып. 23 

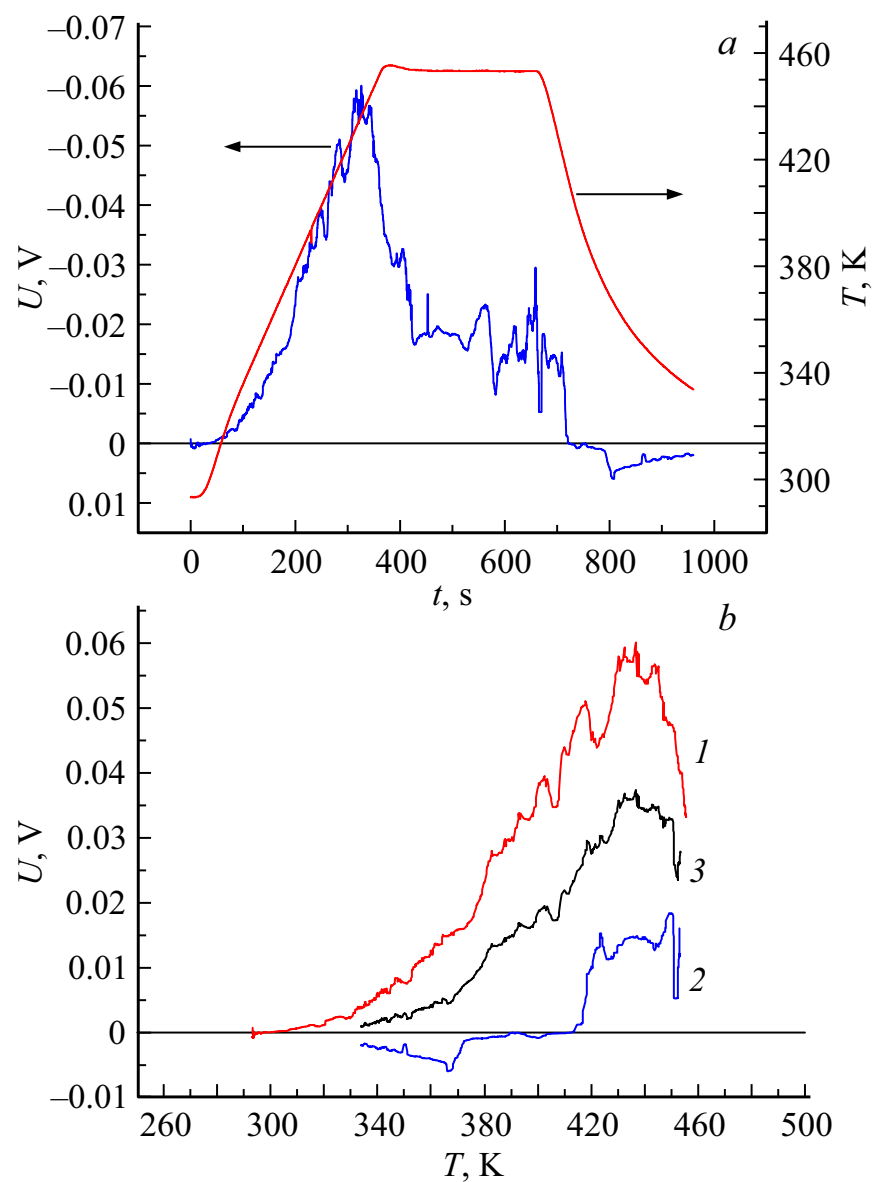

Рис. 2. Результаты измерения термовольтаического эффекта в $\mathrm{Ce}_{2} \mathrm{~S}_{3} . a-$ экспериментальная зависимость генерируемого напряжения в режиме реального времени; $b-$ зависимости генерируемого образцом напряжения от температуры: 1 - нагревание, 2 - охлаждение, 3 - температурная зависимость термовольтаического эффекта.

Полученный результат отображался на мониторе в режиме реального времени. Результаты приведены на рис. 2,a. На рис. 2, $b$ показаны

Письма в ЖТФ, 2018, том 44, вып. 23 
полученные из рис. 2, а температурные зависимости генерируемого образцом напряжения при нагревании (кривая 1) и охлаждении (кривая 2). Эти кривые представляют собой сумму выходного сигнала от термовольтаического эфекта и эффекта Зеебека. Ввиду того что термовольтаический эффект при нагревании и охлаждении не изменяет своего направления, так как не меняет своего направления градиент концентрации донорных примесей, а эффект Зеебека меняет направление на противоположное при изменении направления градиента температуры при нагревании и охлаждении образца, температурная зависимость термовольтаического эффекта будет иметь вид кривой 3 , представляющей собой среднеарифметическое кривых 1 и 2 [7]. Таким образом, термовольтаический эффект достиг величины $37 \mathrm{mV}$ при температуре $436 \mathrm{~K}\left(163^{\circ} \mathrm{C}\right)$.

Для того чтобы оценить максимально возможное значение генерируемого за счет термовольтаического эффекта напряжения в полуторных сульфидах церия можно воспользоваться формулой из работы [8]:

$$
U=\frac{k T}{e} \ln \left(\frac{n_{2}}{n_{1}}\right),
$$

где $n_{1}$ и $n_{2}-$ концентрации электронов при температуре $T$ в приконтактных областях образца. Величину $T$ следует понимать как разницу между текущей температурой и температурой начала эксперимента. Если представить себе, что исследуемый нами образец может иметь в своем составе области с минимальным и максимальным для $\mathrm{Ce}_{2} \mathrm{~S}_{3}$ значениями $n$, которые равны $0.05 \cdot 10^{19}$ и $140 \cdot 10^{19} \mathrm{~cm}^{-3}$ (см. выше), то в этом случае за величины $n_{1}$ и $n_{2}$ можно принять указанные значения, и при $T=436 \mathrm{~K}$ получим максимальную величину генерируемого напряжения $(95 \mathrm{mV})$, которую можно получить на поликристалле $\mathrm{Ce}_{2} \mathrm{~S}_{3}$. Найденная нами величина $37 \mathrm{mV}$ вполне согласуется с расчетными данными, поскольку получение максимальной расчетной величины могло бы произойти только случайным образом. Целенаправленное создание образца с максимальной разницей между $n_{1}$ и $n_{2}$ представляет собой сложную технологическую задачу.

Таким образом, показана возможность обнаружения большого по величине термовольтаического эффекта в $\mathrm{Ce}_{2} \mathrm{~S}_{3}$ при достаточно низких и удобных для исследования температурах $(300-455 \mathrm{~K})$. Это позволяет продолжить исследования в данном направлении.

Письма в ЖТФ, 2018, том 44, вып. 23 


\section{Список литературы}

[1] Каминский В.В., Соловьёв С.М. // ФТТ. 2001. Т. 43. В. 3. С. 423-426.

[2] Пронин И.А., Аверин И.А., Божинова А.С., Георгиева А.Ц., Димитров Д.Ц., Карманов А.А., Мошников В.А., Папазова К.И., Теруков Е.И., Якушова Н.Д. // Письма в ЖТФ. 2015. Т. 41. В. 19. С. 22-28.

[3] Саидов А.С., Лейдерман А.Ю., Каршиев А.Б. // Письма в ЖТФ. 2016. Т. 42. B. 14. C. 21-27.

[4] Голубков А.В., Гончарова Е.В., Жузе В.П., Логинов Г.М., Сергеева В.М., Смирнов И.А. Физические свойства халькогенидов редкоземельных элементов. Л.: Наука, 1973. 304 с.

[5] Zalessky V.G., Kaminski V.V., Hirai S., Kubota Y., Sharenkova N.V. // ФТП. 2018. T. 52. В. 4. C. 435-438.

[6] Каминский В.В. // Письма в ЖТФ. 2013. Т. 39. В. 15. С. 12-17.

[7] Каминский В.В., Казанин М.М., Романова М.В., Каменская Г.А., Шаренкова Н.В. // ФТП. 2016. Т. 50. В. 9. С. 1163-1166.

[8] Каминский В.В., Степанов Н.Н., Соловьёв С.М. // Физика и техника высоких давлений. 2015. Т. 25. № 3-4. С. 74-81.

Письма в ЖТФ, 2018, том 44, вып. 23 